\title{
Analysis on Risk Appetite of Peer-to-Peer Lending Platforms under Market Competition-Based on Extended Hoteling Model
}

\author{
Qi Li ${ }^{1,2, a}$ and Xiaoyan Wang ${ }^{3, b}$
}

\author{
${ }^{1}$ Post-doctoral Research Center, School of Economics, Peking University, Beijing 100871, China; \\ ${ }^{2}$ Post-doctoral Research Center, HuaRong Asset Management Corporation, Beijing 100033, \\ China;
}

${ }^{3}$ School of Business, Suzhou University of Science and Technology, Suzhou 215009, China.

aliqi1989@ruc.edu.cn, b18618486942@163.com

\begin{abstract}
This paper analyzes risk appetite of P2P lending platforms under market competition based on extended Hoteling model. It is shown that there exists a Nash equilibrium in the competition between P2P lending platforms in which all platforms provide only low or high risk bids. Specifically, all platforms will provide high risk bids only when the marginal cost of high risk bids differs greatly between platforms, and provide low risk bids only when the difference is not so obvious. In conclusion, market competition increases risk appetite of P2P lending platforms, which brings about many "problematic platforms" suffering management failures.
\end{abstract}

Keywords: Peer-to-Peer lending, competition, Hoteling model, risk, Nash equilibrium.

\section{Introduction}

Peer-to-Peer (P2P) lending receives extensive attention in both practice and academics. It facilitates investors to lend money directly to borrowers without financial intermediaries such as banks. P2P lending platform itself plays an intermediary role both information ally and transaction ally, and P2P lending market grows at an explosive rate because of its prominent advantages such as low threshold, simple procedure, high flexibility, high rate of return and low financing cost. Although $\mathrm{P} 2 \mathrm{P}$ lending shares still only a small portion of the whole lending market, the number of $\mathrm{P} 2 \mathrm{P}$ lending platforms keeps increasing fast since the first P2P lending platform Zola arose in United Kingdom.

However, this explosive growth also brings various operation and management difficulties, resulting in vast bad debts and even bankruptcy. "Problematic platforms" are the P2P platforms that faces illiquidity, operational difficulty, system collapse and other bankruptcy-related problems. The bankruptcy of these platforms affects not only the profit of investors but also the development of the $\mathrm{P} 2 \mathrm{P}$ industry. Therefore, it is vital to academics as well as practitioners to research effective management method regarding $\mathrm{P} 2 \mathrm{P}$ lending platforms.

Existing researches on the risks of $\mathrm{P} 2 \mathrm{P}$ lending platforms are relatively abundant, both the qualitative analysis on the whole and the quantitative research on one platform. Compared with other risk types, existing research is more focused on operation risk of $\mathrm{P} 2 \mathrm{P}$ lending platform, because the laws and regulations related to $\mathrm{P} 2 \mathrm{P}$ lending platforms are not sound. Existing papers analyze the risk factors of $\mathrm{P} 2 \mathrm{P}$ lending platforms from the perspectives of borrowers, investors and platforms, but lacking of the perspective of market structure. As an independent economic subject to make the optimal response to external environment, a P2P lending platform can make a strategic choice for its own risk appetite when facing fierce market competition. Therefore, by using the extended Hoteling model from the theory of industrial organization, the paper focuses the research on the influence market competition has on the risk appetite of $\mathrm{P} 2 \mathrm{P}$ lending platforms.

\section{Hypotheses of Extended Hotelling Model}

Hoteling (1929) proposes Hoteling model first, which is a game model that researches firms' location and pricing with differentiated commodity by the hypothesis of linear market. Due to the existence of the transfer cost, although manufacturers provide homogeneous commodity, the prices are different for the consumers located in different positions in the linear market. Therefore, for 
manufacturers, commodity price is not simply equal to marginal cost, but considering the transfer cost of consumers in different positions.

For P2P lending market, borrowing demand is far greater than investment demand and the regulation of $\mathrm{P} 2 \mathrm{P}$ lending relatively lags behind. This makes investors cautious about $\mathrm{P} 2 \mathrm{P}$ lending, so the competition in P2P lending platforms reflects in the competition in investors. At present, the profit of $\mathrm{P} 2 \mathrm{P}$ lending platforms intermediary fee drawn from loan interest which depends on the amount borrowed and the term of one "bid". Therefore, there is a reciprocal relationship for the allocation of interest earnings between investors and P2P lending platforms. Investors will turn to other $\mathrm{P} 2 \mathrm{P}$ lending platforms if the intermediary fee charged by the $\mathrm{P} 2 \mathrm{P}$ lending platform is too high. Corresponding to this, if the intermediary fee is too low, the profit of P2P lending platforms may decrease. Hence, there is an optimal pricing problem of intermediary fee for P2P lending platforms in market competition. Due to the information asymmetry between the risk appetite of investors and that of P2P lending platforms, P2P lending platforms can provide different investment bids according to investors' different risk appetite and make different intermediary fees. From the above analysis, the problem of the P2P lending platform competition conforms to the idea of Hoteling model, namely, seeking for the optimal intermediary fee in the market competition according to the investors' different risk appetite. Therefore, by treating the point in the linear market of Hoteling model as the point representing investors' risk appetite and the space distance as the difference of risk appetite ("risk distance"), this paper aims to analyze the risk appetite of P2P lending platforms in market competition though extended Hoteling model. The assumptions of this paper are as follows:

Assumption one: Considering a linear P2P lending market that the "risk distance" is one unit and investors are evenly distributed in the interval $[0,1]$.

Assumption two: Both ends of the linear P2P lending market are two P2P lending platforms. The platform 1 is at point 0 and the platform 2 is at point 2 . Both of them can provide two kinds of risk bids: "a low risk bid" which is lower than all investors' risk appetite in the market and "a high risk bid" which is higher than all investors' risk appetite in the market.

Assumption three: $\mathrm{x}$ represents the risk distance between an investor and the platform 1. 1-x represents the risk distance between the investor and the platform 2. The greater $\mathrm{x}$, the bigger difference of the risk appetite between the investor and the platform 1 and the smaller difference of the risk appetite between the investor and the platform 2 .

Assumption four: $t$ represents the utility loss of one unit risk distance when an investor chooses the bid of the platform 1 (or the platform 2 ). The value range is $(0,1)$.

Assumption five: The marginal costs of the two platforms are common knowledge. For the low risk bid, the marginal costs of the platform 1 and the platform 2 are the same c. But for the high risk bid, the marginal cost of the platform 1 is $\mathrm{c} 1$ and that of the platform 2 is $\mathrm{c} 2$ which are different. The value range of $\mathrm{c}, \mathrm{c} 1$ and $\mathrm{c} 2$ are $(0,1)$.

Assumption six: The linear P2P lending market is an ideal market which means one investor only has one unit investment demand. The net surplus for an investor is $\mathrm{Xu}$ that is large enough related to the sum cost of the investment, and thus one P2P lending platform can cover the whole market.

Assumption seven: The paper introduces the static game model for complete information.

\section{Investment Analysis Based on Extended Hotelling Model}

The following is the investment analysis of the bids provided by the platform 1 and the platform 2 in market competition. Supposing the risk distance is $\mathrm{x}$ between one investor and the platform 1 when the utilities are indifferent that the investor gains from P2P lending investment in the platform 1 and the platform 2, the investors that their risk distances are less than $\mathrm{x}$ will choose the bids provided by the platform 1 while the investors that their risk distances are more than $\mathrm{x}$ will choose the bids provided by the platform 2 . Therefore, the demand functions of the two platforms are $\mathrm{D} 1=\mathrm{x}$ and D2=1-x, respectively. Because both the platforms have two bids: the low risk bid or the high risk bid, this paper points four situations to analyze the equilibrium strategies selected by the two platforms. 


\subsection{Both Platforms Provide the Low Risk Bid}

Because the capacity of producing hard information is the same for the two platforms, the low risk bids provided by the two platforms are also the same no matter which platform one investor in the linear market selects. In this situation, the utility loss of the investor shows a linear relationship with the risk distance, so the extended Hoteling model with single pricing and linear transfer cost is suitable.

The formula of the net surplus is as follows when the investor at point $\mathrm{x}$ selects the low risk bid provided by the platform 1 or the platform 2 :

$$
U_{x}= \begin{cases}v+r-r_{1}-t x & \text { selecting the low risk bid of the platform } 1 \\ v+r-r_{2}-t(1-x) & \text { selecting the low risk bid of the platform } 2\end{cases}
$$

where $v$ represents the investor's reserve price, $r$ represents the bid's interest rate, $r_{1}$ and $r_{2}$ represent the intermediary fees of the platform 1 and the platform 2 , respectively.

Supposing $x$ is the indifference point, it means the net surplus is the same at point $x$ no matter which platform the investor will select. So

$$
v+r-r_{1}-t x=v+r-r_{2}-t(1-x)
$$

The demand functions of the two platforms are

$$
D_{1}=x=\frac{r_{2}-r_{1}+t}{2 t} \quad D_{2}=1-x=\frac{r_{1}-r_{2}+t}{2 t}
$$

The profit functions of the two platforms are

$$
\pi_{1}=\left(r_{1}-c\right) D_{1}=\frac{\left(r_{1}-c\right)\left(r_{2}+t-r_{1}\right)}{2 t} \quad \pi_{2}=\left(r_{2}-c\right) D_{2}=\frac{\left(r_{2}-c\right)\left(r_{1}+t-r_{2}\right)}{2 t}
$$

The first order conditions of the profit maximization are

$$
\frac{\partial \pi_{1}}{\partial r_{1}}=\frac{r_{2}-2 r_{1}+t+c}{2 t}=0 \quad \frac{\partial \pi_{2}}{\partial r_{2}}=\frac{r_{1}-2 r_{2}+t+c}{2 t}=0
$$

The second order conditions are met. The optimal solution of the two platforms' intermediary fees is

$$
r_{1 a}^{*}=r_{2 a}^{*}=t+c
$$

So the equilibrium profits of the two platforms are

$$
\pi_{1 a}^{*}=\pi_{2 a}^{*}=\frac{t}{2}
$$

\subsection{The Platform 1 Provides the Low Risk Bid and the Platform 2 Provides the High Risk Bid}

In this situation, the platform 2 can identify investors' risk appetite accurately and make loan pricing based on different risk appetite. The paper describes the advantage by price discrimination. In addition, the utility loss by one unit risk distance of the investors close to the two platforms in the linear market could be less than that of the investors far from the platforms, because it is different of the risk in bids provided by the platforms and it is similar to the risk appetite of the platforms and the investors close to them. So the quadric relationship between utility loss and risk distance of investors are used to describe the difference. Consequently, the extended Hoteling model with quadratic transfer cost is suitable. The platform 1 uses single price $r_{1}$ and the platform 2 uses price discrimination $r_{2}=c_{2}+t(1-x)^{2}$. So the formula of the net surplus is as follows when the investor at point $x$ selects the low risk bid provided by the platform 1 or the high risk bid provided by the platform 2:

$$
U_{x}=\left\{\begin{array}{l}
v+r-r_{1}-t x^{2} \\
v+r-c_{2}-t(1-x)^{2}
\end{array}\right.
$$

selecting the low risk bid of the platform 1 selecting the high risk bid of the platform 2

Since $x$ is the indifference point, the net surplus is the same at point $x$ no matter which platform the investor will select. So 


$$
v+r-r_{1}-t x^{2}=v+r-c_{2}-t(1-x)^{2}
$$

The demand functions of the two platforms are

$$
D_{1}=x=\frac{c_{2}-r_{1}+t}{2 t} \quad D_{2}=1-x=\frac{r_{1}-c_{2}+t}{2 t}
$$

The profit function of the platform 1 is

$$
\pi_{1}=\left(r_{1}-c\right) D_{1}=\frac{\left(r_{1}-c\right)\left(c_{2}-r_{1}+t\right)}{2 t}
$$

The first order condition of the profit maximization of the platform 1 is

$$
\frac{\partial \pi_{1}}{\partial r_{1}}=\frac{c+c_{2}-2 r_{1}+t}{2 t}=0
$$

The second order condition is met. The optimal solution of the platform 1's intermediary fee is

$$
r_{1 b}^{*}=\frac{1}{2}\left(c+c_{2}+t\right)
$$

$\operatorname{Set} \Delta c_{2}=c_{2}-c$, and in equilibrium, the demand function of the platform 2 and the profit function of the platform 1 are

$$
D_{2 b}^{*}=\frac{t+\Delta c_{2}}{4 t} \quad \pi_{1 b}^{*}=\frac{\left(t+\Delta c_{2}\right)^{2}}{8 t}
$$

In equilibrium, because of price discrimination, the platform 2 only need to set the loan price less than or equal to the price set by the platform 1 for the same investor in order to gain maximum profit. So the optimal intermediary fee of the platform 2 is

$$
r_{2 b}^{*}=r_{1 b}^{*}+t x^{2}, \frac{t+\Delta c_{2}}{4 t}<x \leq 1
$$

In equilibrium, the profit function of the platform 2 is

$$
\pi_{2 b}^{*}=\int_{\frac{t+\Delta c_{2}}{4 t}}^{1}\left[r_{1 b}^{*}+t x^{2}-c_{2}-t(1-x)^{2}\right] d x=\frac{\left(3 t-\Delta c_{2}\right)^{2}}{16 t}
$$

\subsection{The Platform 1 Provides the High Risk Bid and the Platform 2 Provides the Low Risk Bid}

In this situation, the result of the investment analysis is opposite to the second situation above. The platform 1 uses price discrimination $r_{1}=c_{1}+t x^{2}$ and the platform 2 uses single price $r_{2}$. So the formula of the net surplus is as follows when the investor at point $x$ selects the high risk bid provided by the platform 1 or the low risk bid provided by the platform 2 :

$$
U_{x}= \begin{cases}v+r-c_{1}-t x^{2} & \text { selecting the high risk bid of the platform } 1 \\ v+r-r_{2}-t(1-x)^{2} & \text { selecting the low risk bid of the platform } 2\end{cases}
$$

When the net surplus is the same, we can get the demand functions of the two platforms:

$$
D_{1}=x=\frac{r_{2}-c_{1}+t}{2 t} \quad D_{2}=1-x=\frac{c_{1}-r_{2}+t}{2 t}
$$

The profit function of the platform 2 is

$$
\pi_{2}=\left(r_{2}-c\right) D_{2}=\frac{\left(r_{2}-c\right)\left(c_{1}-r_{2}+t\right)}{2 t}
$$

The first order condition of the profit maximization of the platform 2 is

$$
\frac{\partial \pi_{2}}{\partial r_{2}}=\frac{c+c_{1}-2 r_{2}+t}{2 t}=0
$$



is

The second order condition is met. Then the optimal solution of the platform 2's intermediary fee

$$
r_{2 c}^{*}=\frac{1}{2}\left(c+c_{1}+t\right)
$$

$\operatorname{Set} \Delta c_{1}=c_{1}-c$, and in equilibrium, the demand function of the platform 1 and the profit function of the platform 2 are

$$
\begin{gathered}
D_{1 c}^{*}=x=\frac{3 t-\Delta c_{1}}{4 t} \\
\pi_{2 c}^{*}=\frac{\left(t+\Delta c_{1}\right)^{2}}{8 t}
\end{gathered}
$$

In equilibrium, because of price discrimination, the platform 1 only need to set the loan price less than or equal to the price set by the platform 2 for the same investor in order to gain maximum profit. So the optimal intermediary fee of the platform 1 is

$$
r_{1 c}^{*}=r_{2 c}^{*}+t(1-x)^{2}, \quad 0 \leq x \leq \frac{3 t-\Delta c_{1}}{4 t}
$$

In equilibrium, the profit function of the platform 1 is

$$
\pi_{1 c}^{*}=\int_{0}^{\frac{3 t-\Delta c_{1}}{4 t}}\left[r_{2 c}^{*}+t(1-x)^{2}-c_{1}-t x^{2}\right] d x=\frac{\left(3 t-\Delta c_{1}\right)^{2}}{16 t}
$$

\subsection{Both Platforms Provide the High Risk Bid}

In this situation, both the platforms set loan prices based on investors' risk appetite which are described by pricing discrimination. Meanwhile, no matter which platforms the investors will choose, the bids provided by the two platforms are homogeneous. So it is a linear relationship between utility loss and risk distance of investors. The extended Hoteling model with price discrimination and linear transfer cost is suitable.

When the investor at point $x$ selects the high risk bid provided by the platform 1 or the platform 2 , the formula of the net surplus is

$$
U_{x}= \begin{cases}v+r-c_{1}-t x & \text { selecting the high risk bid of the platform } 1 \\ v+r-c_{2}-t(1-x) & \text { selecting the high risk bid of the platform } 2\end{cases}
$$

The market is in equilibrium when the net surplus is the same. At the moment, the demand functions of the two platforms are

$$
D_{1 d}^{*}=x=\frac{c_{2}-c_{1}+t}{2 t} \quad D_{2 d}^{*}=1-x=\frac{c_{1}-c_{2}+t}{2 t}
$$

In equilibrium, the functions of the optimal intermediary fees of the two platforms are

$$
r_{1 d}^{*}=c_{2}+t(1-x), 0 \leq x \leq \frac{c_{2}-c_{1}+t}{2 t} \quad r_{2 d}^{*}=c_{1}+t x, \frac{c_{2}-c_{1}+t}{2 t}<x \leq 1
$$

So the equilibrium profit functions of the two platforms are

$$
\begin{aligned}
& \pi_{1 d}^{*}=\int_{0}^{\frac{c_{2}-c_{1}+t}{2 t}}\left[c_{2}+t(1-x)-c_{1}-t x\right] d x=\frac{\left(c_{2}-c_{1}+t\right)^{2}}{4 t}=\frac{\left(\Delta c_{2}-\Delta c_{1}+t\right)^{2}}{4 t} \\
& \pi_{2 d}^{*}=\int_{\frac{c_{2}-c_{1}+t}{2 t}}^{1}\left[c_{1}+t x-c_{2}-t(1-x)\right] d x=\frac{\left(c_{1}-c_{2}+t\right)^{2}}{4 t}=\frac{\left(\Delta c_{1}-\Delta c_{2}+t\right)^{2}}{4 t}
\end{aligned}
$$




\section{Existence of the Equilibrium Solution}

According to the investment analysis of the four situations in the third part, we can get the profits matrix in equilibrium of the two platforms which is shown in Table 1.

Table 1. The profits matrix in equilibrium of the two platforms with different strategies

\begin{tabular}{|c|c|c|c|}
\hline \multicolumn{2}{|c|}{} & \multicolumn{2}{|c|}{ P2P lending platform 2 } \\
\cline { 2 - 4 } \multirow{2}{*}{$\begin{array}{c}\text { P2P lending } \\
\text { platform 1 }\end{array}$} & Low risk bid & High risk bid \\
\cline { 2 - 4 } & High risk bid & $\frac{t}{2}, \frac{t}{2}$ & $\frac{\left(t+\Delta c_{2}\right)^{2}}{8 t}, \frac{\left(3 t-\Delta c_{2}\right)^{2}}{16 t}$ \\
& Hew & $\frac{\left(t+\Delta c_{1}\right)^{2}}{8 t}$ & $\frac{\left(\Delta c_{2}-\Delta c_{1}+t\right)^{2}}{4 t}, \frac{\left(\Delta c_{1}-\Delta c_{2}+t\right)^{2}}{4 t}$ \\
\hline
\end{tabular}

Note: in the expression of each group, the former is the equilibrium profit of the platform 1 and the latter is the equilibrium profit of the platform 2.

From Table 1, the two P2P lending platforms have four strategy profiles: (low risk bid, low risk bid), (low risk bid, high risk bid), (high risk bid, low risk bid) and (high risk bid, high risk bid). In order to determine the final strategies the two platforms will select, it is necessary to find the solution of the profit matrix in equilibrium.

There are three equilibrium solutions of pure strategy in Table 1: (1) a Nash equilibrium (low risk bid, high risk bid) and (high risk bid, low risk bid); (2) a Nash equilibrium (low risk bid, low risk bid) and (high risk bid, high risk bid); (3) no Nash equilibrium. In order to ensure a universal equilibrium result, the following content considers the equilibrium solution which meets all the possible value of $\mathrm{t}$ within $(0,1)$. Under this condition, for all $\mathrm{t} \in(0,1)$, there exists the Nash equilibrium (low risk bid, low risk bid) and (high risk bid, high risk bid).

\section{Conclusion}

This paper analyzes risk appetite of Peer-to-Peer lending platforms under market competition based on extended Hoteling model to provide an explanation of the prevalent "problematic platforms". It is concluded that a Nash equilibrium exists in the competition between P2P lending platforms. One platform will provide low risk bid when other platforms provide low risk bids and provide high risk bid when other platforms provide high risk bids. Further, the strategy profiles of the Nash equilibrium shows that all the platforms will provide high risk bids only when the marginal cost of the high risk bids differs greatly between platforms, and provide low risk bids only when the difference is not so obvious .

$\mathrm{P} 2 \mathrm{P}$ lending is an emerging thing and $\mathrm{P} 2 \mathrm{P}$ lending platforms are in the savage growth period. The number of P2P lending platforms climbs year by year from the first P2P lending platform Zola founded in British in 2005, Prosper founded in United States in 2006 and Paipaidai founded in China in 2007. Especially since 2012, the number of China's new P2P lending platforms has been a multiple of geometric growth, but the yearly number of $\mathrm{P} 2 \mathrm{P}$ lending platforms that failed is doubled. At present, $\mathrm{P} 2 \mathrm{P}$ lending industry is not yet mature. There is a large gap on the background, capital scale, operation ability and risk control level between P2P lending platforms, and the same as the identification ability and the development cost of the high risk bid. Because of the higher profit of the high risk bid for investors and platforms, market competition will make platforms tend to increase risk appetite and provide high risk bid in order to obtain high profit. Therefore, the "problematic platforms" will emerge constantly and platform failures happen frequently due to the lack of platforms' risk appetite management. 


\section{References}

[1]. S. Freedman and G.Z. Jin, "Do social networks solve information problems for peer-to-peer lending? Evidence from prosper. Com", 2008-11-14.

[2]. S.M. Freedman and G.Z. Jin, "Learning by Doing with Asymmetric Information: evidence from Prosper. Com", National Bureau of Economic Research, 2011.

[3]. E. Lee and B. Lee, "Herding behaviour in online P2P lending: An empirical investigation", Electronic Commerce Research and Applications, vol.11, no.5, pp. 495-503, 2012.

[4]. L. Liao, M.R. Li and Z.W. Wang, "The intelligent investor: not-fully-marketed interest rate and risk identify: evidence from P2P lending", Economic Research Journal, no. 7, pp. 125-137, 2014.

[5]. S.D. Luo and R. Wang, "Research on the supervision of P2P risk", Economic Review, no. 9, pp. 28-31, 2014.

[6]. X. Lu and H.M. Li, "Operation mode and risk control of P2P network lending", Reform, no. 2, pp. 60-68, 2015.

[7]. H. Hoteling, "Stability in Competition", Economic Journal, no. 39, pp. 41-57, 1929.

[8]. C. D'Aspremont, J.J. Gabszewicz and J.F. These "On Hoteling's" Stability in competition", Econometrical, vol. 47, no. 47, pp.1145-1150, 1979.

[9]. Z.H. Deng and B.Y. Wu, "Price discrimination with switching costs and banking competition: a study based on the Hoteling model", On Economic Problems, no. 9, pp. 19-22, 2011. 